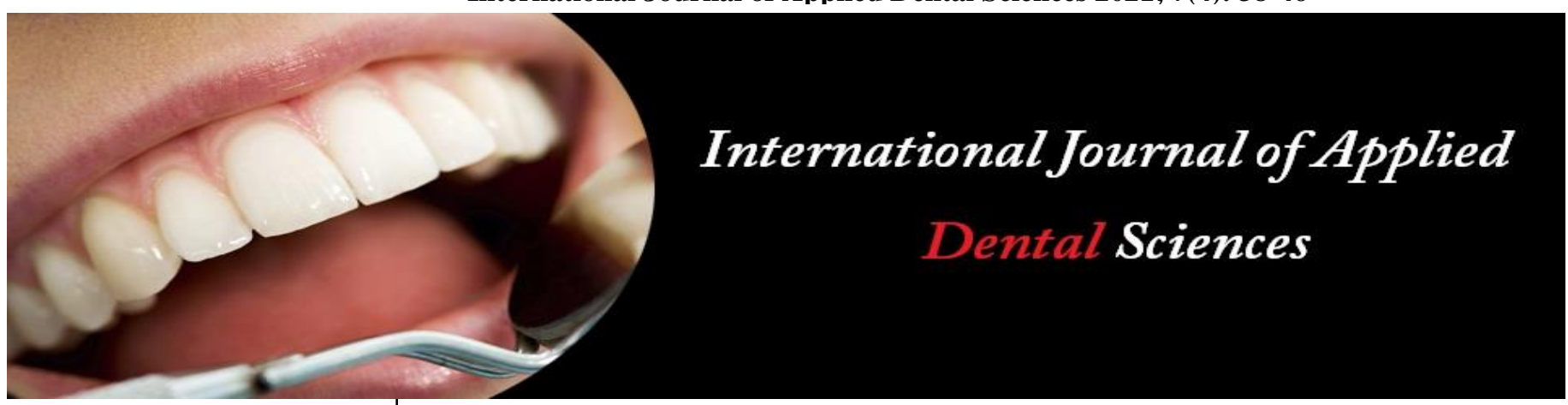

ISSN Print: 2394-7489

ISSN Online: 2394-7497

IJADS 2021; 7(4): 38-46

(C) 2021 IJADS

www.oraljournal.com

Received: 28-08-2021

Accepted: 30-09-2021

Dr. Manpreet Kaur Sandhu MDS (Conservative Dentistry and Endodontics), Consultant Endodontist, Fortis Hospital, Mohali, Punjab, India
Corresponding Author: Dr. Manpreet Kaur Sandhu MDS (Conservative Dentistry and Endodontics), Consultant Endodontist, Fortis Hospital, Mohali, Punjab, India

\section{Techniques for removal of intracanal separated instruments (Part 2)}

\section{Dr. Manpreet Kaur Sandhu}

DOI: $\underline{\text { https://doi.org/10.22271/oral.2021.v7.i4a.1351 }}$

\section{Abstract}

Intracanal instrument separation thwarts the ongoing treatment process adding to woes of the dentist as well as the patient because it trammels the cleaning, shaping and filling of root canals. This captiously affect the outcome of endodontic treatment by building more impediments, thus compromising the prognosis. Therefore clinicians must be aware of the possibility of instrument fracture in endodontic practice to stave off this mishap. This article quotes narrative review accentuating the techniques for retrieval of intracanal separated instruments along with factors influencing its removal. (Different techniques for removal of Gutta Percha from root canal system has been discussed in detail in part 1 by the same author).

Keywords files, retreatment, rotatry instruments, separated instruments

\section{Introduction}

According to Torabinejad [1], the manufacturing defects in files are rare. The causes of intracanal instrument separation includes overuse or excessive force applied to the files (main cause), limited flexibility and strength of intracanal instruments combined with improper use.

Sattapan et al. ${ }^{[1]}$ addressed that 2 main causes of breakage of rotary $\mathrm{Ni}$-Ti files are cyclic fatigue and torsional stress. Cyclic fatigue occurs when the file is freely rotating in a canal and flexes until fracture occurs which clinically, corresponds to the most curved portion of the root. Torsional stress occurs when the tip or any other part of the file is locked or bound within a canal while the shaft continues to rotate. Sattapan et al. ${ }^{[2]}$ noted that torsional stress occurred in $55.7 \%$ and cyclic fatigue occurred in $44.3 \%$ of the fractured files that were evaluated.

Pruett and colleagues ${ }^{[3]}$ stated that the instrument size as well as radius and angle of curvature play a role in cyclic fatigue.

Rotational speed of the instrument has also been shown to contribute to cyclic fatigue. With higher rotational speed, the time to file failure decreases significantly ${ }^{[4,5]}$.

Di Fiore PM ${ }^{[6]}$ put forth 12 measures to prevent NiTi rotary instrument fracture during root canal preparation which includes:

1. avoid subjecting NiTi rotary instruments to excessive stress;

2. use instruments that are less prone to fracture;

3. follow an instrument use protocol;

4. assess root canal curvatures radiographically and instrument them carefully;

5. ensure that endodontic access preparation is adequate;

6. open orifices before negotiating canals;

7. enlarge root canals with fine hand instruments;

8. set rotational speed and torque at low levels;

9. use crown-down technique;

10. irrigate and lubricate root canals during preparation;

11. manipulate rotary instruments with a pecking motion;

12. If inexperienced, engage in preclinical training in use of rotary instruments. 
Techniques for removal of intracanal separated instruments

\section{Mini Forceps}

With sufficient space present within the root canal system, an instrument separated in a more coronal portion of the root canal can be grasped and removed by using forceps ${ }^{[7,8,9]}$ such as Steiglitz forceps (Fig. 1a), Peet silver point forceps, Endo forceps (Fig. 1b) or endo micro-forceps (Fig. 1c).

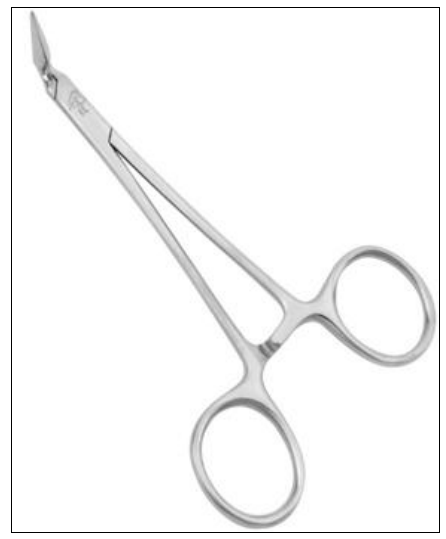

Fig 1a: Steiglitz forceps

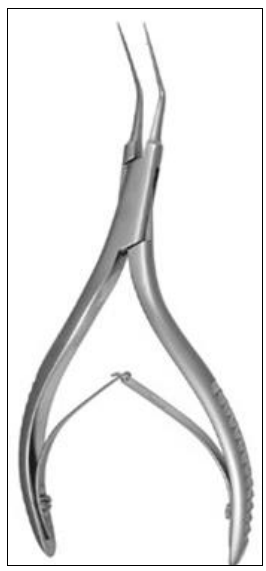

Fig 1b: Endo forceps long thin tips are bent at a $60^{\circ}$ angle to the handle

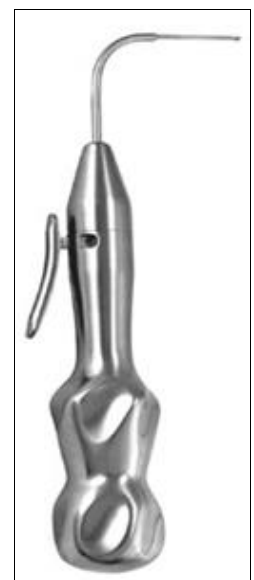

Fig 1c: Endo micro-forcep long thin tip is bent at a $90^{\circ}$ angle to the handle

\section{Braiding technique of endodontic files}

$\mathrm{H}$ or $\mathrm{K}$ files can be inserted into root canal to engage the fragment and then withdraw it when the fragment is positioned deeply in the canal and not visible and the clinician is relying on tactile sense, or the fragment is loose but cannot be retrieved by using other means ${ }^{[8,10]}$.

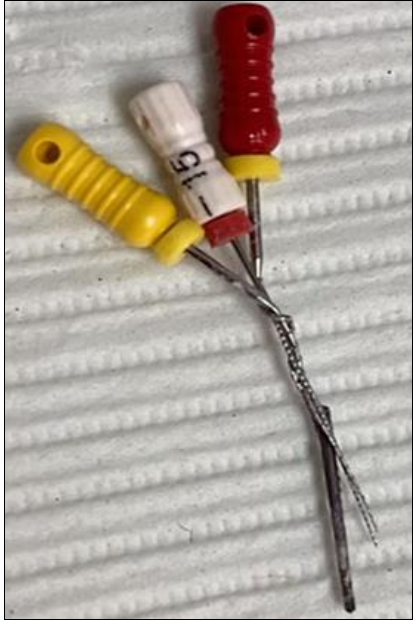

Fig 2: Braiding technique of endodontic files

\section{Wire Loop method}

A wire loop can be formed by passing the 2 free ends of a 0.14 -mm wire through a 25 -gauge injection needle from the open end until they slide out of the hub end (Fig. 3a, 3b). By using a small hemostat, the wire loop is tightened around the upper free part of the fragment, and then whole assembly can be withdrawn from the root canal (Fig. 3c). The loop can be either small circular or long elliptical in shape, according to canal size and the location of the fragment. This technique can be used to retrieve objects that are not tightly bound in the root canal ${ }^{[9,11]}$.

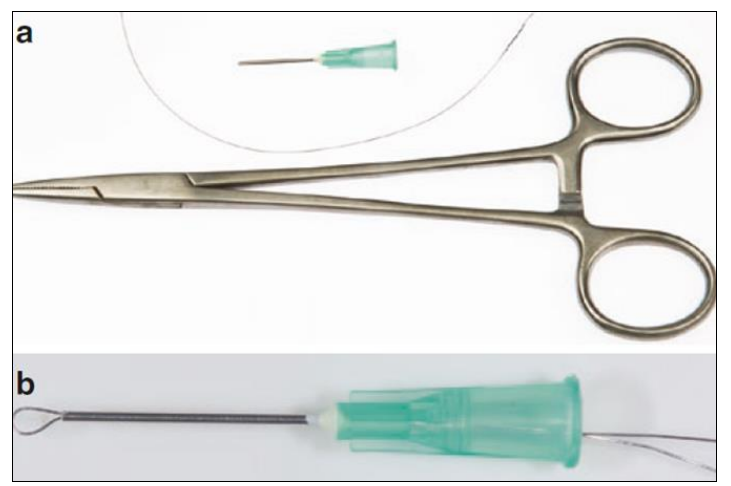

Fig 3a, b: Armamentarium required in the wire loop technique includes a cut disposable needle, an orthodontic wire, and small hemostatic forceps a loop formed

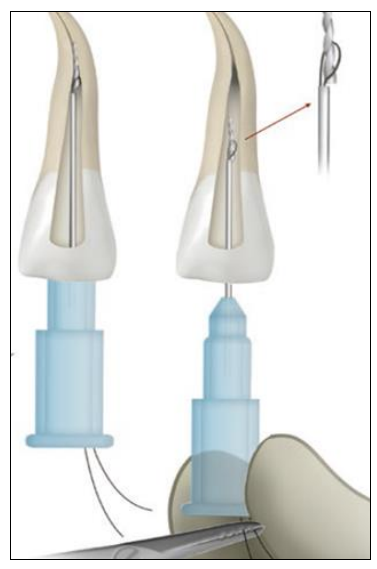

Fig 3c: Prepared loop is oriented according to the existing space and tightened around the fragment in the canal. Once positioned, the hub of the needle is held with the other hand. Both free ends of the wire are clamped with the hemostatic forceps and tightened. Then complete assembly is moved back and forth until the segment is loosened and can be removed 


\section{Broach and Cotton}

If the separated fragment is a barbed broach (Fig. 4) and not tightly wedged in the root canal, another small barbed broach with a small piece of cotton roll twisted around it can be inserted inside the root canal to engage the fragment; then the whole assembly is withdrawn ${ }^{[7]}$.

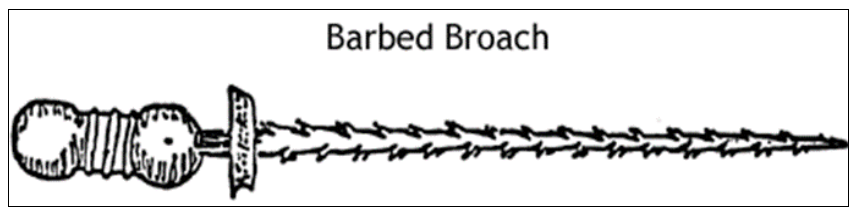

Fig 4: Barbed broach

\section{Hypodermic Surgical Needles}

The beveled tip of a hypodermic needle can be shortened to cut a groove around the coronal part of the fragment by rotating the needle under light apical pressure (Fig. 5a). The needle size should allow its lumen to entirely encase the coronal tip of the fragment ${ }^{[12]}$. The groove (trough) around the fragment can also be prepared by using thin ultrasonic tips or trephine burs. To remove the fragment, a cyanoacrylate glue or strong dental cement (eg, polycarboxylate) can be inserted into the hypodermic needle, and then (when set) the complex (needle-adhesive-fragment) can be pulled out delicately in a clockwise or counterclockwise rotational movement ${ }^{[13]}$. If glue cannot be used, then a $\mathrm{H}$ file can be pushed in a clockwise turning motion through the needle to wedge the upper part of the fragment and the needle's inner wall (Fig. 5b) ${ }^{[9]}$.

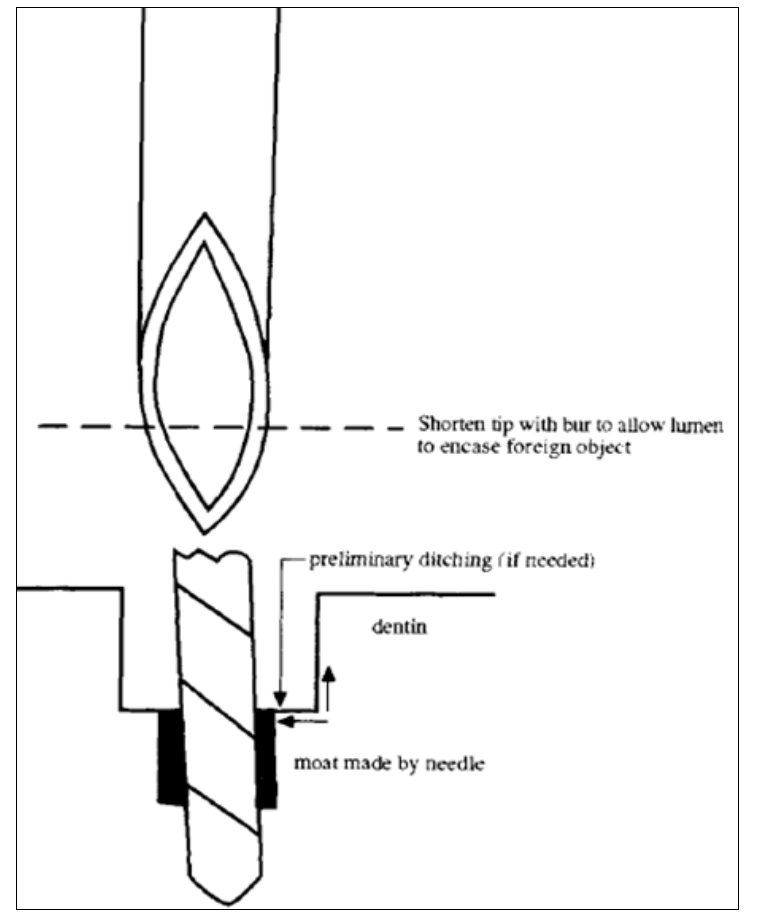

Fig 5a: Foreign object diameter guides corresponding needle lumen for conservative circumferential cutting of dentin

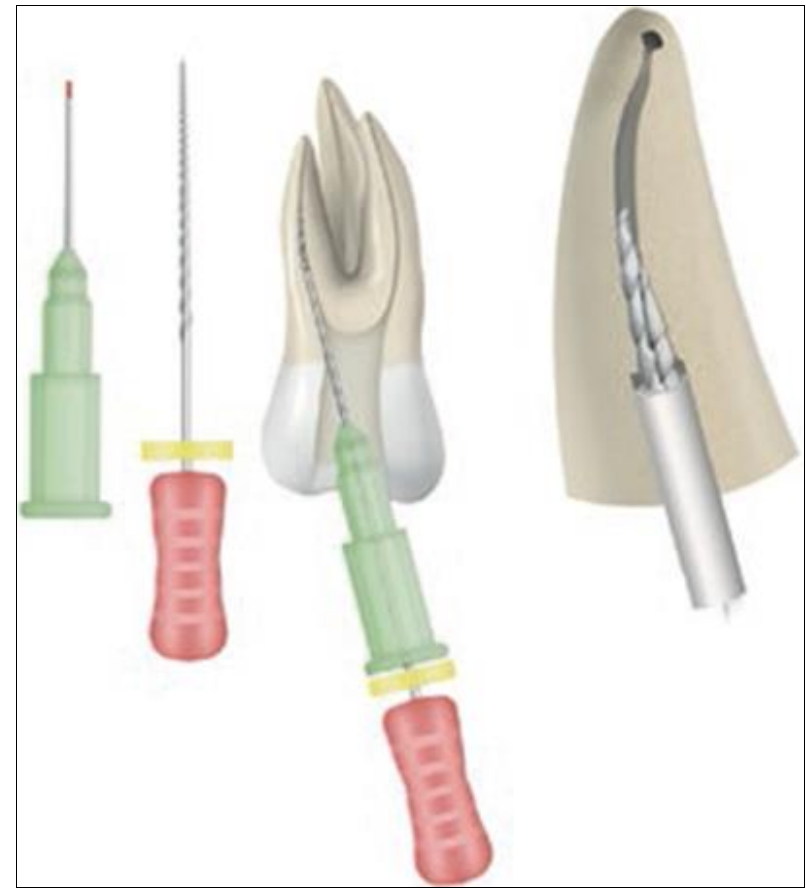

Fig 5b: $\mathrm{H}$ file is introduced into canal through already inserted hypodermic needle over the exposed 1-2 mm coronal segment of fragment. Then $\mathrm{H}$ file is tightly engaged between the fragment and internal lumen of needle. Thus, the three connected objects are then withdrawn from the canal by pulling the needle and $\mathrm{H}$ file

\section{Masserann Instruments}

The Masserann kit (Micro-Mega, Besanc, on, France) consists of 14 hollow cutting-end trephine burs (sizes 11-24) ranging in diameter from 1.1-2.4 mm (Fig. 6a) and 2 extractors tubes into which a plunger can be advanced (Fig. $6 b)$. The trephines burs are used in a counterclockwise fashion to prepare a groove (trough) around the coronal portion of the fragment. When inserted into the groove and tightening the screw, the free part of the fragment is locked between the plunger and the internal embossment. The relatively large diameters of extractors $(1.2$ and $1.5 \mathrm{~mm}$ ) require removal of a considerable amount of dentin, which may weaken the root and lead to perforation or postoperative root fracture. This largely restricts the use of Masserann instruments to anterior teeth ${ }^{[9,14,15,16]}$.

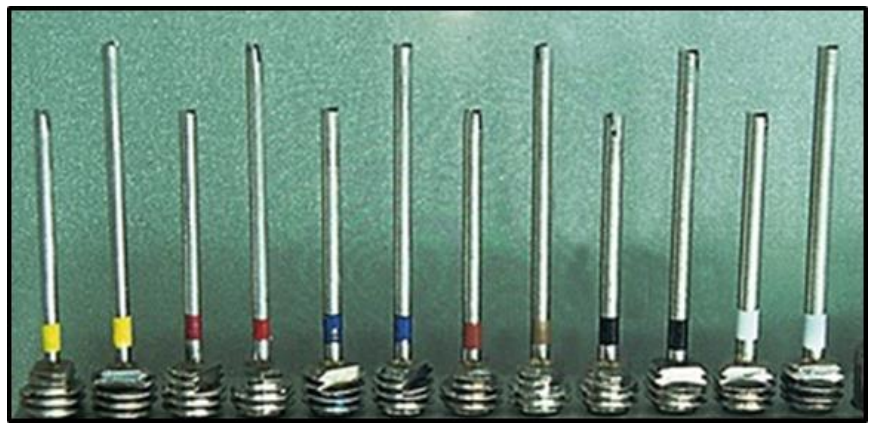

Fig 6a: Trephine burs 


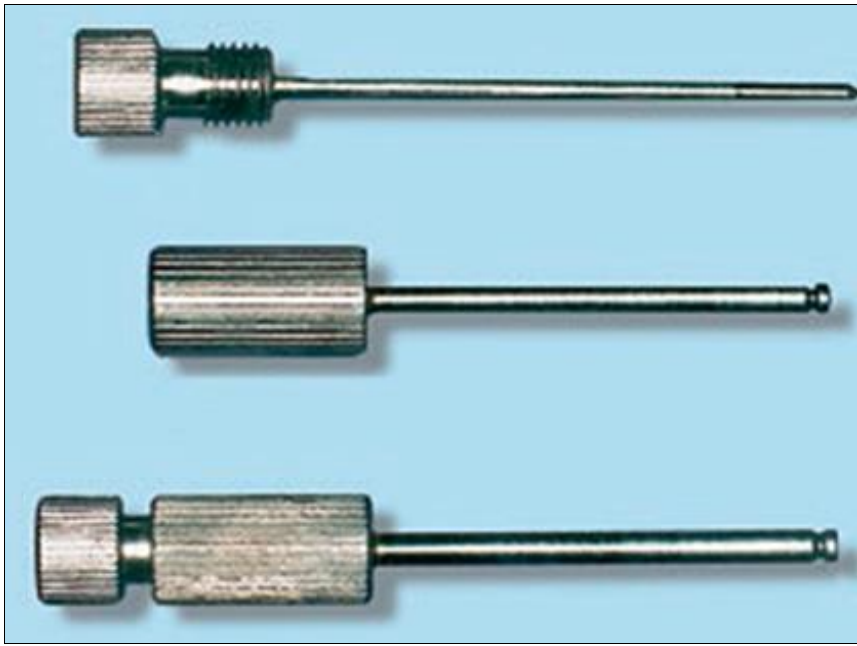

Fig 6b: Plunger, extractor tube shown separately and then plunger inserted inside tube

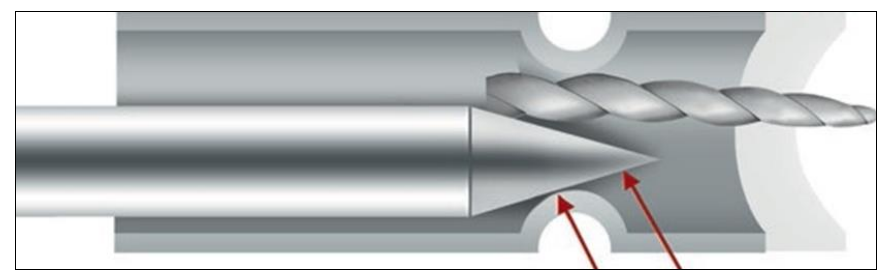

Fig 6c: Space between the extractor tube and plunger, grips an instrument fragment (tip of the plunger shown by double arrow)

\section{Extractors}

The concept behind the Masserann technique has been further developed, and new extractors have been introduced. This includes:

(i) Instrument Removal System (Dentsply Tulsa Dental, Tulsa, OK) contains 3 extractors. The black extractor/ microtube has an outside diameter of $1 \mathrm{~mm}$ and is used in the coronal one third of larger root canals. The red and yellow microtubes $(0.80$ and $0.60 \mathrm{~mm}$, respectively) are used in narrower canals (Fig. 7a). ${ }^{9}$, The screw wedge has knurled metal handle and is inserted into corresponding microtube which has a rubber handle (Fig. 7b) [17] Microtube is beveled at 45 degree to scoop out the separated instrument with a side window for efficient engaging (Fig. 7c).

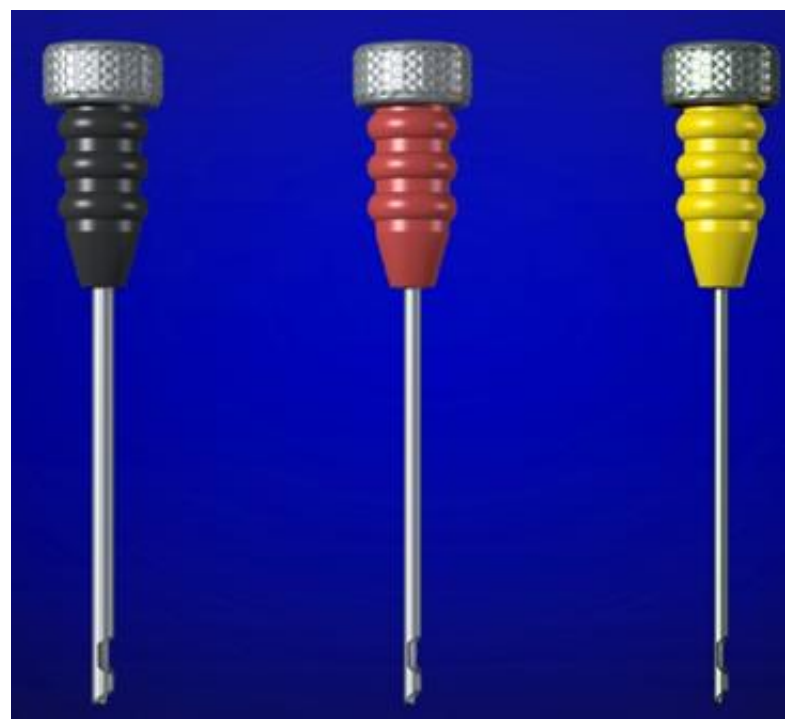

Fig 7a: Color coded microtubes with corresponding screw wedges inserted

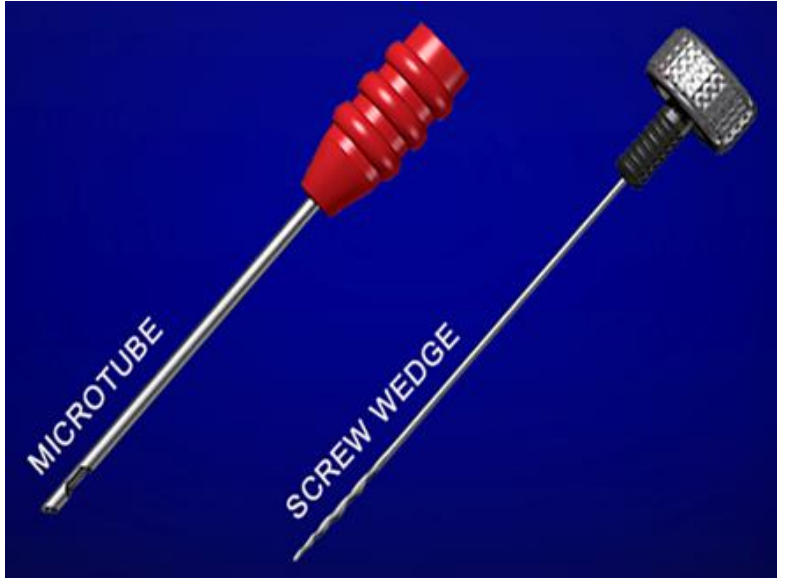

Fig 7b: Microtube and screw wedge shown separately

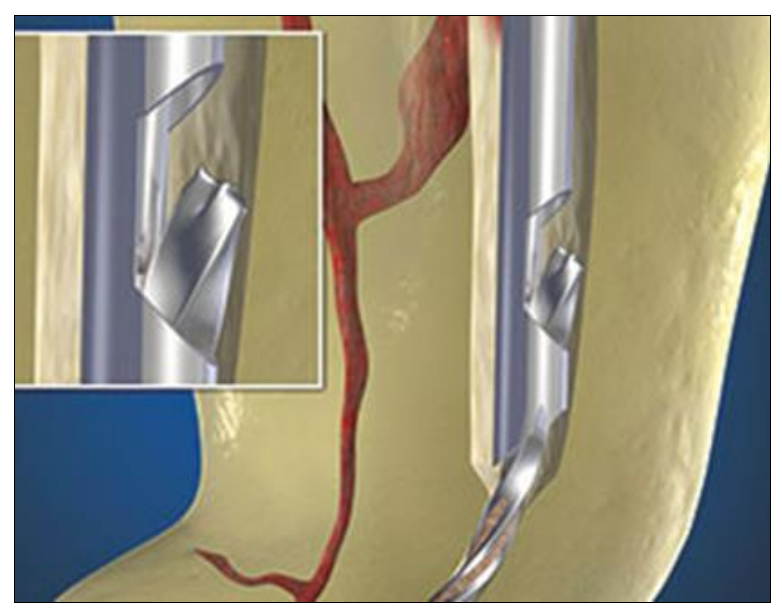

Fig 7c: Graphic shows that a same color-coded screw wedge is inserted into the micro-tube until it makes contact with the fragment and is turned counterclockwise to mechanically engage and displace the head of the fragment through the side window

(i) Endo- Extractor system (Roydent) has 3 extractors of different sizes and colors (red 80, yellow 50, and white 30). Each extractor has its corresponding trephine bur that prepares a groove around the separated instrument.

(ii) Cancellier Extractor Kit (SybronEndo, Orange, CA) contains 4 extractors with outside diameters of $0.50,0.60$, 0.70 , and $0.80 \mathrm{~mm}$.

(iii) Endo Rescue (Komet/Brasseler, Savannah, GA) consists mainly of a center drill called Pointier that excavates dentin coronal to the fragment and trephine burs that rotate in a counterclockwise direction to remove the fragment. These instruments are available in 2 sizes, 090 (red) and 070 (yellow).

(iv) Meitrac Endo Safety System (Hager and Meisinger $\mathrm{GmbH}$, Neuss, Germany) is another new system that has 3 sizes of tubes.

\section{Ultrasonics}

Ultrasonic instruments have a contra-angled design with alloy tips of different lengths and sizes to enable use in different parts of the root canal (Fig. 8a) ${ }^{[18]}$. A staging platform is prepared around the most coronal aspect of the fragment by using modified Gates Glidden burs (no. 2-4) ${ }^{[19]}$. Gates Glidden bur is modified by grinding the bur perpendicular to its long axis at its maximum cross-sectional diameter (Fig. $8 b$ ). The ultrasonic tip is activated at lower power settings, so it trephines dentin and the vibration being transmitted to the fragment, makes latter to loosen and then "jumps" out of the 
root canal. Other root canal orifices in the tooth, when present, should be blocked with cotton pellets to prevent the entry of loose fragment. Excessive pressure may push the fragment apically or the ultrasonic tip may fracture, so, it is important to avoid unnecessary stress by only activating it when in contact with root tissue ${ }^{[20,21,22]}$.

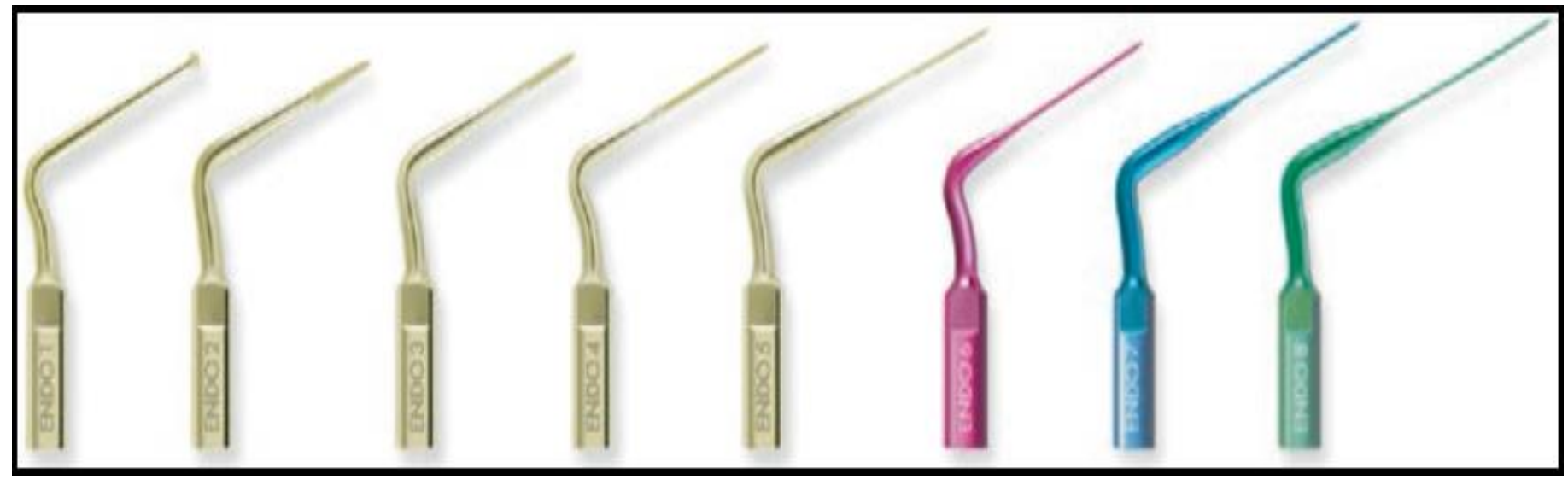

Fig 8a: Pro Ultra ENDO Tips (Dentsply Tulsa Dental, Tulsa, OK) no. 1-5 are zirconium nitride coated for removal of dentin and restorative materials along the lateral sides of the instruments. ProUltra ENDO 6-8 are titanium coated used to the full length of root canal due to their longer length and smaller diameter

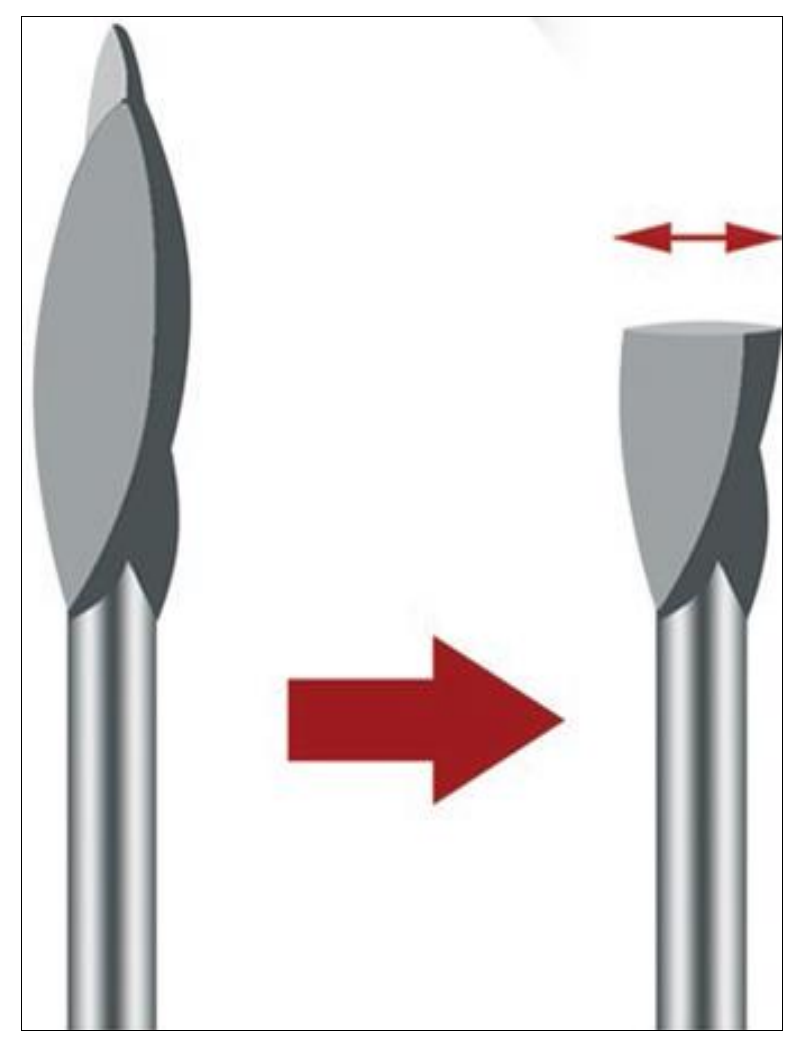

Fig 8b: Gates glidden drill cut perpendicular to long axis at its maximum cross sectional diameter to create a 'staging platform'

\section{Canal Finder System}

The original Canal Finder System [23] (FaSociete Endo Technique, Marseille, France) consisted of a hand piece and specially designed files producing vertical movement with maximum amplitude of 1-2 $\mathrm{mm}$ that decreases when the speed increases ${ }^{\text {[24] }}$ (Fig. 9a). It effectively aids in bypassing a fragment, but should be used carefully to not perforate the root or apically extrude the fragment, especially in curved root canals. The flutes of the file can mechanically engage the separated fragment, and with the vertical vibration, the fragment can be loosened or even retrieved ${ }^{[25]}$. This system has been recently replaced by the Endo Pulse system in which SS files are used in vertical reciprocation and a passive $1 / 4$ turn motion (Fig. 9b) ${ }^{[22]}$.

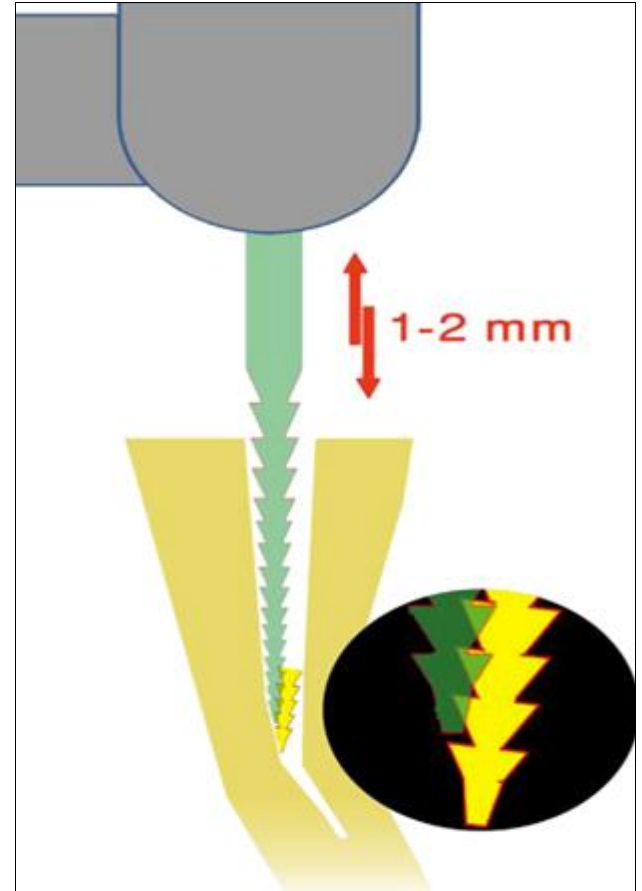

Fig 9a: Canal Finder System has a handpiece and specially designed files that produces a 1 to $2-\mathrm{mm}$ up-and-down movement to engage with the fragment, and with this up-and-down motion, the fragment can be loosened or even retrieved

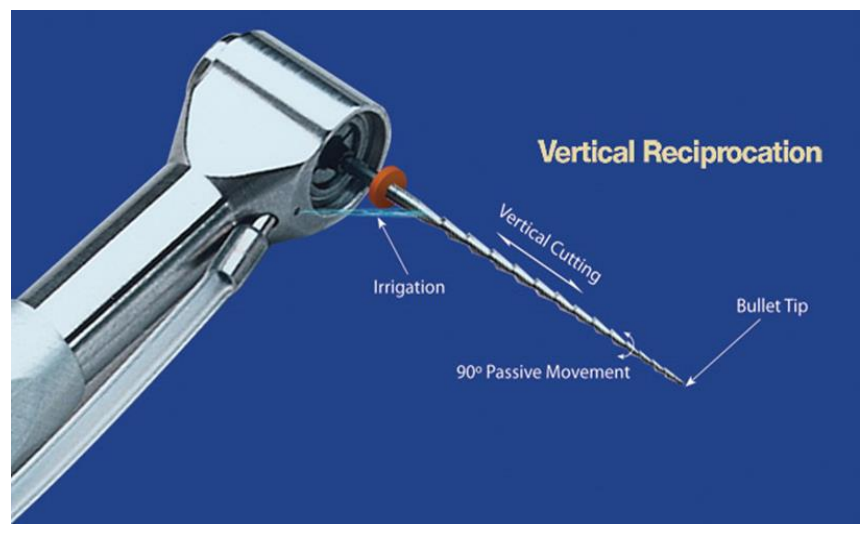

Fig 9b: Endo Pulse head (close-up illustration) demonstrates vertical reciprocation, $90^{\circ}$ passive movement, and irrigation (cavitation) 


\section{File Retrieval System}

The Terauchi File Retrieval Kit ${ }^{[26]}$ (TFRK, Dental Care, Santa Barbara, California, USA) was introduced in 2006 (Fig. 10 a):

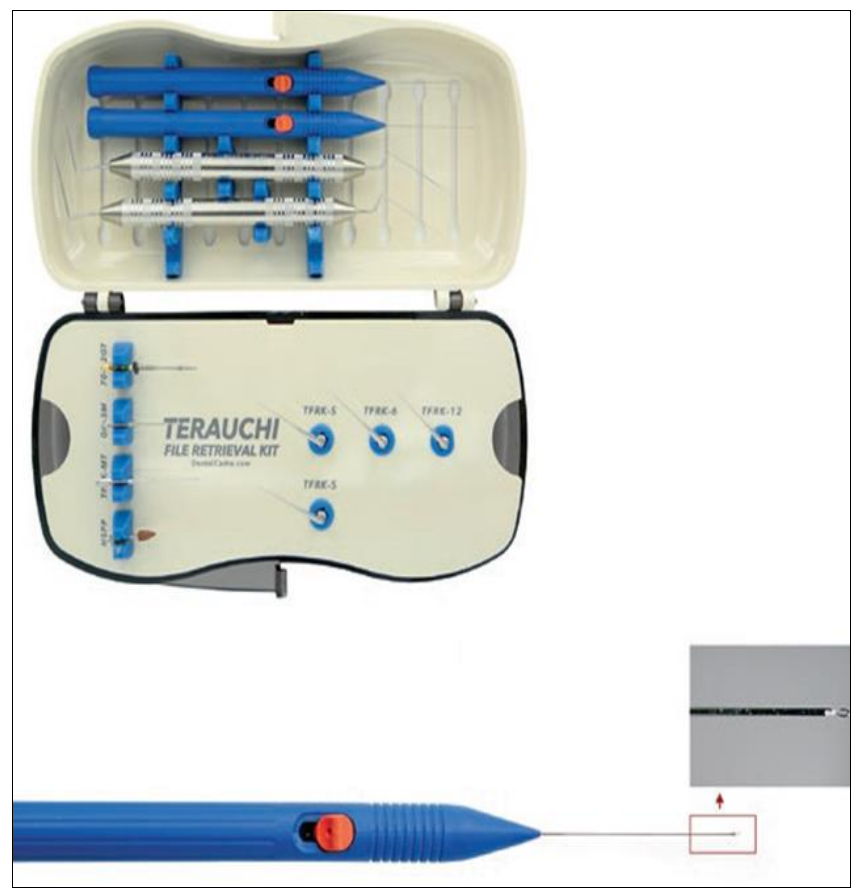

Fig 10a: Terauchi File Retrieval Kit (TFRK, Dental Care, Santa Barbara, California, USA)
This system involves three steps that consists of three different techniques and three newly designed instruments ${ }^{26}$ illustrated in (Fig. 10b).

Step 1 - Two types of low-speed cutting burs with 28-mm lengths are used. The first one is referred to as Cutting Bur a (CBA) which has a pilot tip that follows the path already created by the separated file when it was first brought into the canal before the breakage. It is used to enlarge the canal wall so that the second bur can be easily introduced into the canal and brought into contact over the coronal portion of the separated file. The second bur is referred as Cutting Bur B (CBB) which has a cylinder-shaped tip that cuts the periphery of the separated file, which acts as a trephine bur that slightly machines down the coronal portion of the file. At the same time, this provides a guidance space for the ultrasonic tip that is subsequently used in the second step. The diameter of the CBA is $0.5 \mathrm{~mm}$ while the diameter of the CBB is $0.45 \mathrm{~mm}$. Both burs can go around a curved canal as they are flexible in the shanks.

Step 2 - Ultrasonic tip (30 mm long and $0.2 \mathrm{~mm}$ diameter) is used to prepare a groove around the separated fragment (at least $0.7 \mathrm{~mm}$ deep). This usually loosens the fragment or even removes it or else step 3 is carried out.

Step 3 - A loop device with a NiTi wire $(0.08 \mathrm{~mm})$ is used to mechanically engage the peripherally exposed (by at least 0.7 $\mathrm{mm}$ ) fragment and retrieve it.

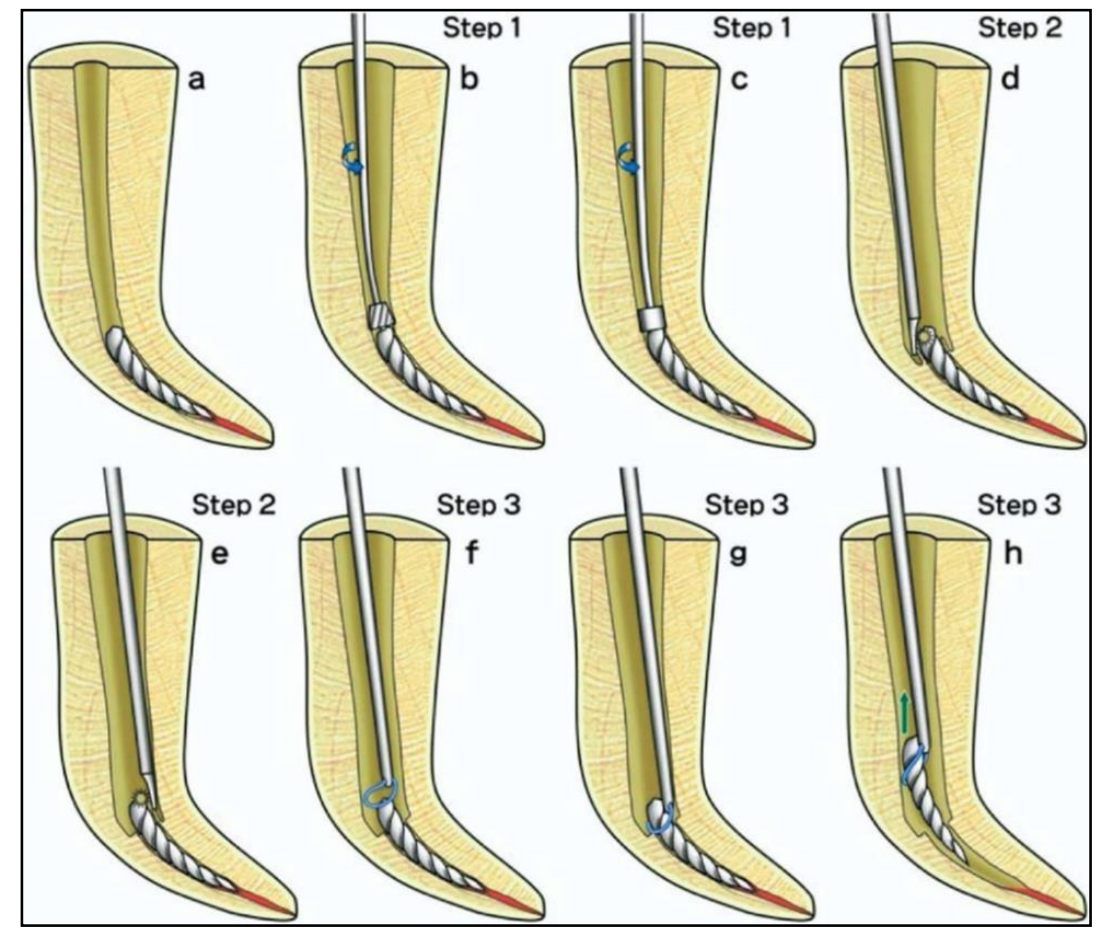

Fig 10b: (a) Initial canal with a separated file. (b) Canal enlarged with CBA. (c) Dentin removal around the separated file with CBB. (d) Ultrasonic tip troughed semicircularly around the separated file to create space for the file-removal device. $(e)$ troughing semicircularly on the remaining half of the separated file for complete exposure. $(f)$ Placement of the loop over the separated file. $(g)$ Fastening the loop to grab the separated file. $(h)$ Removal of the separated file from the root canal

\section{Softened Gutta Percha point method}

Rahimi and Parashos [27] reported a novel and simple technique to remove loose fragments in the apical third of the root canal by using softened gutta-percha (GP) points. SS H files \#8, \#10 and \#15 are initially used to partially bypass the fragment and to check that it is loose. Then, the apical 2-3 $\mathrm{mm}$ of a size 40, 0.04 taper GP point, or different size and taper according to the canal accommodating the fragment, is dipped in chloroform for approximately 30 seconds. The softened GP is then inserted to the maximum extent into the canal and is allowed to harden for approximately 3 minutes. The GP point and the fragment can be then removed by using a delicate clockwise and counterclockwise pulling motion. 


\section{Electrolytic technique}

This aims to partially or even totally dissolve the fragment through electrolysis, thus enabling the recovery of the original canal path to the apex. For this purpose, a system of electrodes is inserted into the root canal so that the anode comes into contact with the fragment of the instrument (Fig. 11) ${ }^{[9]}$. Electrolytes used with the technique include normal saline, sodium hypochlorite in various concentrations, and saline with $0.1 \mathrm{~N}$ hydrochloric acid. Clinical and experimental in vitro and in vivo studies (Ito 1983; Saito et al. 1986; Ito et al. 1987; Okawauchi 1993) ${ }^{[28,29,30,31]}$ have demonstrated that this technique:

- More effective

- When the electrolyte contains hydrochloride acid.

- On carbon steel than on SS instruments.

- When the voltage is increased from 3 to $9 \mathrm{~V}$.

- Less effective when the fragment is lodged in the apical third.

- Safe, as histologic examination did not reveal inflammation in periapical tissues. Deposits of $\mathrm{Fe}$ and $\mathrm{Cr}$, mostly in the apical third, are found.

The major disadvantages of this technique are ${ }^{[9,22]}$

- Long time required for complete fragment dissolution

- limitedroot canal space to accommodate the electrodes

- $\quad$ Need for special equipment

- Use of acid in the electrolyte and its limited effectiveness on SS instruments.

Regardless of the electrolyte used, contact between the fragment and the electrode used as the anode is absolutely essential ${ }^{[32]}$.

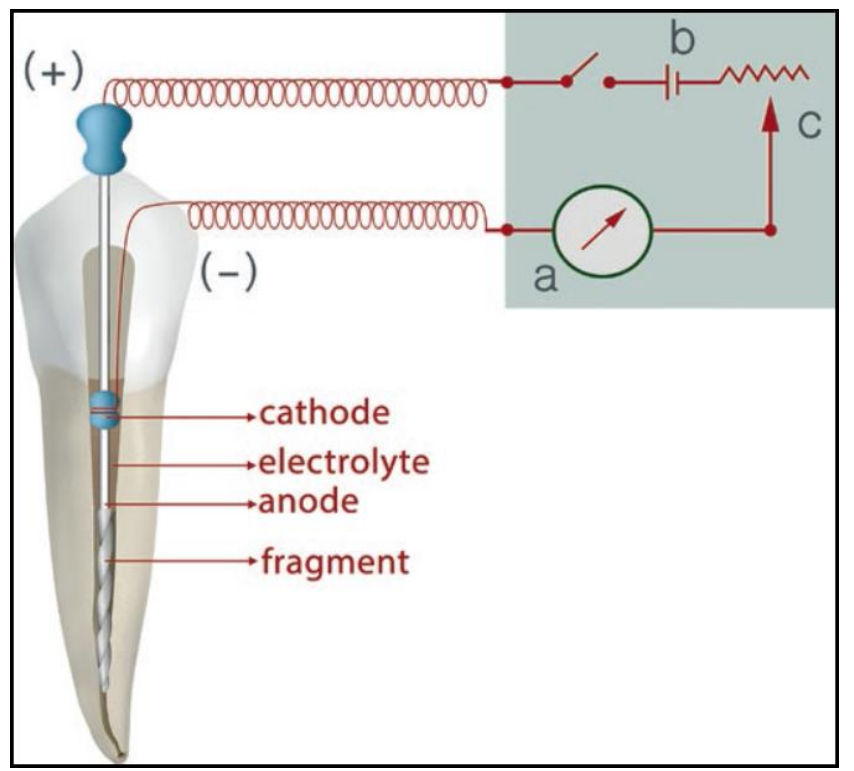

Fig 11: Schematic illustration of the electrolytic technique. (a) Meter (mA). (b) Battery (c) Voltage regulator

\section{Laser Irradiation (Laser-Assisted Removal of Fractured Instruments)}

The Nd: YAG laser has been tested in laboratory studies for removal of separated instruments ${ }^{[33,34]}$. It is claimed that minimum amounts of dentin are removed, reducing the risk of root fracture. Also the fragments can be removed in a relatively short time (less than 5 minutes) in following ways:

1) Laser melts the dentin around the fragment and then $\mathrm{H}$ files are used to bypass and then remove it,

2) Fragment is melted by the laser.
3) Laser welds the file fragment positioned within a metal hollow tube (e.g. Endo-Eze ${ }^{\circledR}$ Tip, Ultradent Products; Fig. 12) ${ }^{[35]}$

However, there is probability of root perforation in curved root canals or thin roots and the temperature rise on the external root surface (up to $27{ }^{\circ} \mathrm{C}$ ), with the potential of periodontal tissue damage ${ }^{[33,34]}$. In addition, heat generated within the root canal can carbonize or even burn dentin, which in turn may disturb the close contact or bond between the filling materials and root canal walls ${ }^{[33]}$.

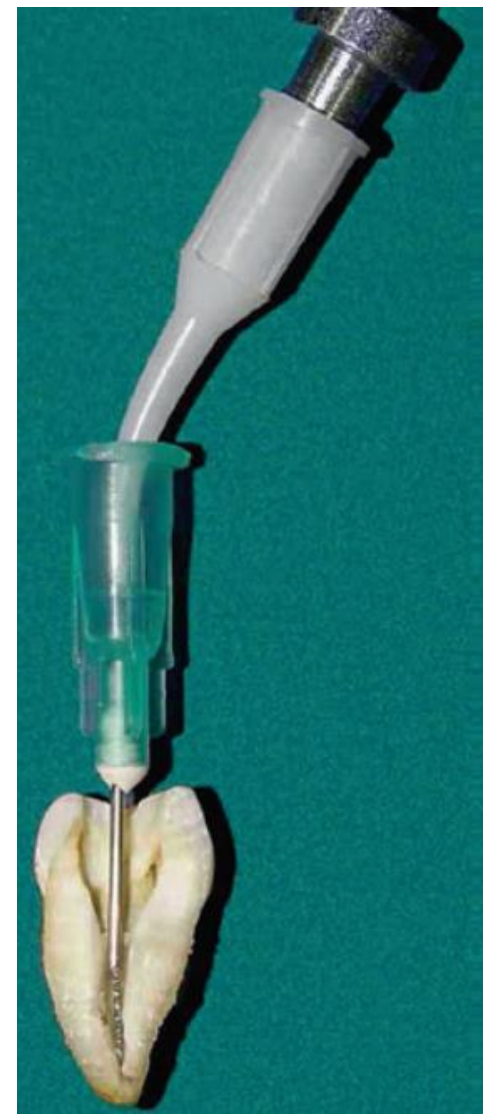

Fig 12: Welding of separated K-type file in Endo-Eze® Tip (18 gauge) using $\mathrm{Nd}$ : YAG laser irradiation at $400 \mathrm{~mJ}$ and $10 \mathrm{~Hz}$

Factors influencing removal of separated instruments 1. Tooth factors

Removal of separated instruments is more predictable in the following situations:

- maxillary teeth ${ }^{[8,36]}$

- anterior teeth ${ }^{[8,36,37]}$

- fragment extends into the coronal third of the root canal $[8,36,37,38]$

- fragment is located before the root canal curvature ${ }^{[8,36-39]}$

- instrument separates in straight or slightly curved root canals $^{[8,36-40]}$

\section{Separated instrument factors (Type, Design, and Length)}

NiTi rotary instruments are more difficult to remove than SS ones ${ }^{[37,41,42]}$ as NiTi:

(Type)

- Tend to thread into root canal walls because of their rotary movement ${ }^{[39]}$.

- Have greater tendencies to fracture repeatedly during removal procedures, particularly when ultrasonics is used [41-43]. 
- Fragments of NiTi instruments in curved root canals tend to lie against the outer root canal wall and do not remain in the center of the canal because of their flexibility ${ }^{[15,17,}$ 40]

\section{(Length)}

- Usually fracture in short lengths, especially after torsional failure ${ }^{[39]}$

- Longer the fragment, higher the success rate of retrieval because longer fragments are usually more coronally located ${ }^{[24]}$.

\section{(Design)}

- K-file is easier and more successful than $\mathrm{H}$ files as $\mathrm{H}$ files have larger helix angle, deeper flutes, and greater positive rake angle

- $\mathrm{H}$ files having greater cutting efficiency than $\mathrm{K}$ files, which may result in greater engagement in root canal walls at the time when separation occurs ${ }^{[36,37,44]}$.

\section{Operator factors}

Successful removal is a challenge that relies on knowledge, training, familiarity with techniques and instruments, perseverance, and creativity. If a clinician believes that he/she does not have the competence for successful management, referring the patient to a specialist would be the preferred approach ${ }^{[17,26]}$.

\section{Patient factors}

- extent of mouth opening,

- limitations in accessing the tooth,

- time constraints,

- anxiety level, and

- motivation to retain teeth ${ }^{[22]}$

\section{Conclusion}

It is important for the clinician to inform the patient if an instrument fractures during treatment or if a fractured file is discovered during a routine radiographic examination or retreatment procedures. The foremost approach should be non-surgical management of instrument fracture by retrieval of the fragment. If this fails, then bypassing the fragment is considered. If this also goes in vain, then instrumentation and obturation of the canal up to the fragment should be carried out.

Surgical management is performed as a

- Last resort when the conservative approach fails, post treatment disease develops and tooth is strategically important in oral cavity.

- First option if periapical pathosis is present and instrument separated in early stage of instrumentation.

\section{References}

1. Torabinejad M, McDonald NJ. Endodontic surgery. In: Torabinejad M, Walton RE, eds. Endodontics Principles and Practice, 4th ed. St Louis: Elsevier Health Sciences 2009, 357-75.

2. Sattapan B, Nervo GJ, Palamara JE et al. Defects in rotary nickel-titanium files after clinical use. J Endod 2000;26:161-165.

3. Pruett JP, Clement DJ, Carnes DL Jr. Cyclic fatigue testing of nickel-titanium endodontic instruments. J Endod 1997;23:77-85.

4. Li UM, Lee BS, Shih CT et al. Cyclic fatigue of endodontic nickel-titanium rotary instruments: static and dynamic tests. J Endod 2002;28:448-451.

5. Martin B, Zelada G, Varela P et al. Factors influencing the fracture of nickel-titanium rotary instruments. Int Endod J 2003;36:262-266.

6. Di Fiore PM. A dozen ways to prevent nickel-titanium rotary instrument fracture. $\mathrm{J}$ Am Dent Assoc 2007;138:196-201.

7. Feldman G, Solomon C, Notaro P, Moskowitz E. Retrieving broken endodontic instruments. J Am Dent Assoc 1974;88:588-91.

8. Shen Y, Peng P, Cheung GS. Factors associated with the removal of fractured NiTi instruments from root canal systems. Oral Surg Oral Med Oral Pathol Oral Radiol Endod 2004;98:605-10.

9. Lambrianidis T. Therapeutic Options for the Management of Fractured Instruments. In Management of Fractured Endodontic Instruments. Springer, Cham 2018, 75-195.

10. Suter B, Lussi A, Sequeira P. Probability of removing fractured instruments from root canals. Int Endod $\mathrm{J}$ 2005;38:112-23.

11. Roig-Greene JL. The retrieval of foreign objects from root canals: a simple aid. J Endod 1983;9:394-7.

12. Eleazer PD, O'Connor RP. Innovative uses for hypodermic needles in endodontics. $\mathrm{J}$ Endod 1999;25:190-1.

13. Johnson WB, Beatty RG. Clinical technique for the removal of root canal obstructions. J Am Dent Assoc 1988;117:473-6.

14. Nagai O, Tani N, Kayaba Y et al. Ultrasonic removal of broken instruments in root canals. Int Endod $\mathbf{J}$ 1986;19:298-304.

15. Ruddle CJ. Nonsurgical retreatment. J Endod 2004;30:827-45.

16. Friedman S, Stabholz A, Tamse A. Endodontic retreatment: case selection and technique - 3: retreatment techniques. J Endod 1990;16:543-9.

17. Ruddle CJ. Nonsurgical endodontic retreatment. J Calif Dent Assoc 2004;32:474-84.

18. Plotino G, Pameijer CH, Grande NM, Somma F. Ultrasonics in endodontics: a review of the literature. J Endod 2007;33:81-95.

19. Ruddle C. Microendodontics: eliminating intracanal obstructions. Oral Health 1997;87:19-21, 23-4.

20. D'Arcangelo C, Varvara G, De Fazio P. Broken instrument removal: two cases. J Endod 2000;26:368-70.

21. Krell KV, Fuller MW, Scott GL. The conservative retrieval of silver cones in difficult cases. J Endod 1984;10:269-73.

22. Madarati AA, Hunter MJ, Dummer PM. Management of intracanal separated instruments. Journal of endodontics 2013;39(5):569-81.

23. Levy G. [Canal Finder System 89: improvements and indications after 4 years of experimentation and use]. Rev Odontostomatol (Paris) 1990;19:327-36.

24. H€ulsmann M. Methods for removing metal obstructions from the root canal. Endod Dent Traumatol 1993;9:22337.

25. H€ulsmann M. Removal of fractured root canal instruments using the Canal Finder System. Dtsch Zahnarztl Z 1990;45:229-32.

26. Terauchi Y, O'Leary L, Suda H. Removal of separated files from root canals with a new file-removal system: case reports. J Endod 2006;32(8):789-97.

27. Rahimi M, Parashos P. A novel technique for the removal 
of fractured instruments in the apical third of curved root canals. Int Endod J 2009;42:264-70.

28. Ito $\mathrm{K}$. The effect of voltage and electrolyte on the dissolubility of separated root canal instrument by electrolytic method. Jpn J Conserv Dent 1983;26:178.

29. Ito K, Mototsugu O, Nishihara H, Shiono M, Hattori N, Asano M, Yamashita Y, Takahashi T, Saito T. A study on broken instrument removal from root canal. Influence of voltage on the dissolubility, current and temperature change. Jpn J Conserv Dent 1987;30:172.

30. Saito T, Yamaguchi M, Tamura K, Tanabe K, Nagai S, Ito $\mathrm{K}$. A clinical study of removing the separated root canal instrument by electrolytic method. Jpn J Conserv Dent 1986;29:81-95.

31. Okawauchi T. Removal of separated instruments from the root canal. The change of $\mathrm{Fe}, \mathrm{Cr}, \mathrm{Ca}$, and $\mathrm{P}$ on the root canal by electrolytic method. Jpn J Conserv Dent 1993;36:562.

32. Ormiga F, Aboud LR, Gomes JA. Electrochemicalinduced dissolution of nickel-titanium endodontic instruments with different designs. Int Endod $\mathbf{J}$ 2015;48(4):342-50.

33. Yu DG, Kimura Y, Tomita Y et al. Study on removal effects of filling materials and broken files from root canals using pulsed Nd: YAG laser. J Clin Laser Med Surg 2000;18:2-8.

34. Ebihara A, Takashina M, Anjo T, et al. Removal of root canal obstructions using pulsed Nd:YAG laser. ICS Lasers in Dentistry 2003;1248:257-9.

35. Tomov G, Kissov H. Laser-assisted endodontic retreatment. Evidences and critique. On-line J Bulgarian Dent Assoc 2014 (in Bulgarian).

36. H€ulsmann M, Schinkel I. Influence of several factors on the success or failure of removal of fractured instruments from the root canal. Endod Dent Traumatol 1999;15:2528

37. Cuje J, Bargholz C, H€ulsmann M. The outcome of retained instrument removal in a specialist practice. Int Endod J 2010;43:545-54.

38. Tzanetakis GN, Kontakiotis EG, Maurikou DV, Marzelou MP. Prevalence and management of instrument fracture in the postgraduate endodontic program at the Dental School of Athens: a five-year retrospective clinical study. J Endod 2008;34:675-87.

39. Ward JR, Parashos P, Messer HH. Evaluation of an ultrasonic technique to remove fractured rotary nickeltitanium endodontic instruments from root canals: an experimental study. J Endod 2003;29:756-63.

40. Gencoglu N, Helvacioglu D. Comparison of the different techniques to remove fractured endodontic instruments from root canal systems. Eur J Dent 2009;3:90-5.

41. Ruddle CJ. Broken instrument removal: the endodontic challenge. Dent Today 2002;21:70-2.

42. Suter B, Lussi A, Sequeira P. Probability of removing fractured instruments from root canals. Int Endod $\mathbf{J}$ 2005;38:112-23.

43. Madarati AA, Qualtrough AJ, Watts DC. Factors affecting temperature rise on the external root surface during ultrasonic retrieval of intracanal separated files. J Endod 2008;34:1089-92.

44. Himel VT, Levitan ME. Use of nickel titanium instruments for cleaning and shaping root canal systems. Tex Dent J 2003;120:262-8. 